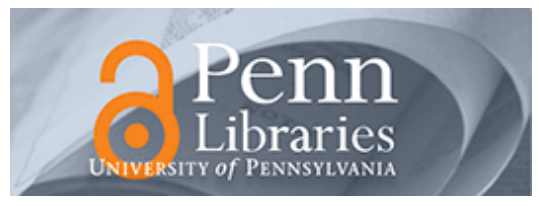

University of Pennsylvania

ScholarlyCommons

Marketing Papers

Wharton Faculty Research

6-2005

\title{
Shades of Meaning: The Effect of Color and Flavor Names on Consumer Choice
}

Elizabeth G. Miller

Barbara E. Kahn

University of Pennsylvania

Follow this and additional works at: https://repository.upenn.edu/marketing_papers

Part of the Advertising and Promotion Management Commons, Behavioral Economics Commons, Business Administration, Management, and Operations Commons, Cognition and Perception Commons, Cognitive Psychology Commons, Marketing Commons, and the Sales and Merchandising Commons

Recommended Citation

Miller, E. G., \& Kahn, B. E. (2005). Shades of Meaning: The Effect of Color and Flavor Names on Consumer Choice. Journal of Consumer Research, 32 (1), 86-92. http://dx.doi.org/10.1086/429602

This paper is posted at ScholarlyCommons. https://repository.upenn.edu/marketing_papers/278

For more information, please contact repository@pobox.upenn.edu. 


\title{
Shades of Meaning: The Effect of Color and Flavor Names on Consumer Choice
}

\author{
Abstract \\ Building on Grice's (1975) theory of "conversational implicature," we propose that consumers will react \\ favorably to unusual color or flavor names (e.g., blue haze or Alpine snow) because they expect marketing \\ messages to convey useful information. If the message is not informative or does not conform to \\ expectations, consumers search for the reason for the deviation. This search results in additional \\ (positive) attributions about the product, and thus, a more favorable response. The results of a series of \\ experiments provide empirical support for our proposal and rule out some alternative explanations for the \\ success of ambiguous naming strategies.

\section{Keywords} \\ preferences, judgment and decision making, experimental design and analysis (ANOVA) \\ Disciplines \\ Advertising and Promotion Management | Behavioral Economics | Business | Business Administration, \\ Management, and Operations | Cognition and Perception | Cognitive Psychology | Marketing | Sales and \\ Merchandising
}


Shades of Meaning: The Effect of Color and Flavor Names on Consumer Choice

\author{
ELIZABETH G. MILLER
}

BARBARA E. KAHN* 
*Elizabeth G. Miller is assistant professor of marketing at Boston College, 140 Commonwealth Ave., Chestnut Hill, MA 02467 (milleliz@bc.edu). Barbara E. Kahn is the Dorothy Silberberg Professor of Marketing, The Wharton School, University of Pennsylvania, Philadelphia, PA 19104 (kahn@wharton.upenn.edu). Correspondence: Elizabeth Miller. This work was supported by a Wharton-SMU research center grant from Singapore Management University. We also thank participants at Singapore Management University for comments during a research seminar. 
Building on Grice's (1975) theory of "conversational implicature," we propose that consumers will react favorably to unusual color or flavor names (e.g., blue haze or Alpine snow) because they expect marketing messages to convey useful information. If the message is not informative or does not conform to expectations, consumers search for the reason for the deviation. This search results in additional (positive) attributions about the product, and thus, a more favorable response. The results of a series of experiments provide empirical support for our proposal and rule out some alternative explanations for the success of ambiguous naming strategies. 
An examination of the colors in a Crayola crayon box reveals an interesting phenomenon - while the original Crayola crayons box contained six colors (black, blue, brown, green, orange, and red), Crayola now offers 120 different colors, and the most recent of these (e.g., purple heart, razzmatazz, tropical rain forest, fuzzy wuzzy brown) are increasingly ambiguously named. These types of ambiguous color (and flavor) names have been proliferating and are appearing in all sorts of product categories from ice-cream (e.g., Ben and Jerry's Chubby Hubby) to juice drinks (e.g., Gatorade's Glacier Freeze) to nail polish (e.g., Hard Candy's Trailer Trash), leading at least one reporter to exclaim, "there is no red" (Schulz 2001). In this article, we propose a 2x2 framework for categorizing these color and flavor names based on whether they are typical or atypical and specific or unspecific. We name the four resulting categories as follows - Common (typical, unspecific; e.g., dark green, light yellow), Common Descriptive (typical, specific; e.g., pine green, lemon yellow), Unexpected Descriptive (atypical, specific; e.g., Kermit green, rainslicker yellow), and Ambiguous (atypical, unspecific; e.g., friendly green, party yellow) and develop a theory to explain how such names impact consumers' product perceptions and purchase intentions.

Building on Grice's (1975) theory of "conversational implicature," we propose that consumers will react favorably to unusual color or flavor names because they expect marketing messages to convey useful information. If the message is not informative (as is the case for the ambiguous names) or does not conform to expectations (as is the case for unexpected descriptive names), consumers search for the reason for the deviation. This search results in additional (positive) attributions about the product, and thus, a more favorable response.

Whether consumers make additional attributions about the product will depend on the informativeness of the available information which is a function of the name's typicality and 
specificity, as well as the existence of any additional information to help identify the color shade or flavor (e.g., picture of the color). Specifically, we propose consumers will be more likely to make these attributions for ambiguous names when the picture of the color is unavailable. Ambiguous names are uninformative in a literal sense, and thus when consumers encounter them, they search for the pragmatic reason for the communication effort. We would not expect such a search to occur when a picture of the color is available, as the given information is no longer uninformative. For unexpected descriptive names, the presence of a picture may increase the number of attributions, since this information may increase curiosity about why the particular adjective was chosen. We do not expect specificity and/or additional information to impact preferences for familiar names.

We present two pilot studies in which the only identifier of the colors or flavors of the stimuli are the descriptive names. In these two pilot studies, we show that consumers prefer atypical and unspecific (ambiguous) names to more typical and more specific names (common descriptives). In the main experiment, we show that ambiguous names are only preferred when the color or flavor is not revealed through some other mechanism prior to showing the name. However, unexpected descriptives are not undermined by the revelation of the color or flavor (prior to the name), and in fact are preferred under those circumstances. We also rule out some alternative explanations in these studies.

\section{ALTERNATIVE COGNITIVE THEORIES FOR EFFECTIVENESS OF COLOR OR FLAVOR NAMES}

Theory of Conversational Implicature 
According to Grice's (1975) theory of conversational implicature, conversations are guided by a set of tacit assumptions. These assumptions enable people to mean more than they say and to make sense of sentences that might literally be seen as non sequiturs. Specifically, Grice argues that listeners interpret speakers' utterances based on the assumption that the speaker is being cooperative, unless they have reason to believe otherwise. For example:

Suppose A asks, 'where is Bill?' and B responds, 'There's a yellow VW outside Sue's home.' If taken literally B's contribution fails to answer A's question - but rather than assume B changed the topic, we infer that Bill probably has a yellow VW and the location of that yellow VW may suggest Bill is at Sue's house. (Levinson 1983, p. 102)

The key assumption inherent in Grice's theory is that all information contributed by participants is relevant to the goal of the ongoing conversation. Schwarz (1996) has shown that people make these assumptions in additional situations (e.g., research experiments) as well, and argues that the assumption that information is relevant is relatively automatic and occurs outside of conscious awareness. However, the subsequent evaluation of that information is not automatic, but rather deliberate and cognitive. Similarly, we hypothesize that consumers may assume that all information offered to them by the marketer is meant to be relevant or informative and they will consequently try to make sense of it. If the ambiguous name is uninformative in the literal or semantic sense, consumers will search for a pragmatic meaning or reason for the communication (Gruenfeld and Wyer 1992; Harris and Monaco 1978). In a marketing context, focusing on a pragmatic meaning would suggest that consumers search for positive information about the product. If the color name is informative and helps the consumer better visualize the color shade, there would be no reason to form these additional positive attributions. Therefore, we hypothesize that ambiguous color or flavor names will yield more positive attributions about the product than will common, informative color or flavor names (cf. 
Carpenter, Glazer, and Nakamoto 1994). These additional positive attributions should then lead to a higher opinion of the product and an increased likelihood of purchase. We refer to this theory as the "Gricean hypothesis."

Incongruency Theory

According to incongruency theory, people make judgments by evaluating new encounters against existing expectations. When encounters are incongruent with prior expectations, individuals will engage in more effortful or elaborative processing to resolve the incongruency (Heckler and Childers 1992). Generally, preferences are thought to be related to incongruity in an inverted-U shaped manner (Meyers-Levy, Louie, and Curren 1994). Specifically, Mandler (1982) posits that congruent items will produce mildly favorable responses with little arousal because no resolution is required. In contrast, Mandler predicts that moderate incongruity will lead to more extensive processing as people try to resolve and find meaning in the incongruity. Such incongruity can make items appear more interesting leading to positive valuations; in addition, such items may receive a positive boost due to the person feeling good for having "solved" the incongruity. Extreme incongruity will also lead to increased processing, but such incongruity is unlikely to be resolved leading to feelings of frustration and helplessness and consequently, negative valuations (Meyers-Levy et al. 1994). Applied to the context of flavor and color names, this theory suggests that when consumers encounter an unfamiliar name which is counter to their expectation that the marketer would be providing a familiar name, they try to determine how the adjective describes the color/flavor. If they discover the connection, the consumer may congratulate himself for solving the problem, resulting in positive affect. The 
most positive affect should result when the name is mildly incongruent. We refer to this theory as the "Incongruency Explanation."

These theories need not be mutually exclusive. It is possible both these theories operate, but under different conditions. Specifically, we propose characteristics of the name itself will influence which process occurs, with a Gricean process observed for names which are uninformative in a literal sense and an incongruency process observed for names which are unfamiliar due to their atypicality. We test this central hypothesis in our main experiment.

\section{FIRST PILOT STUDY}

The purpose of the first pilot study is to assess in a realistic setting whether flavor names influence choice. In this first pilot study, we examine the two extreme conditions of our 2 x 2 matrix of color names. We compare atypical-unspecific names to typical-specific names. We predict that ambiguous (atypical-unspecific) names will be preferred to more common descriptive (typical-specific) names. In addition, we test whether the mechanism driving our results is cognitive by examining decisions under high and low cognitive load. If ambiguous names influence decisions via a cognitive route, then one would expect to see a preference for items with ambiguous names when cognitive load is low and consumers have the ability to process the names, but not when cognitive load is high, preventing elaboration.

Method 
The experiment used a $2 \times 2$ between-subjects design. The first factor was name type: typical-specific (common descriptive) and atypical-unspecific (ambiguous). The second factor was cognitive load (low, high). The flavor names used are listed in the appendix. One hundred undergraduates participated in the experiment as a course requirement.

Participants first participated in an unrelated study that was administered via computer. After completing the study, participants were told that to thank them for their participation they could have some jelly beans that were available in an adjacent room. Participants entered the jelly bean room one-at-a-time and were directed to a table which had six different cups filled with jelly beans. Participants were told to take as many jelly beans as they would like. Each cup was filled with a different flavored jelly bean and had a sign attached to it: half saw ambiguous flavor names and the other half saw the common descriptive names.

Participants in the low cognitive load condition then chose their jelly beans and left. Participants in the high cognitive load condition were told that there had been a glitch in the computer program and we had failed to record the experimental cell the participant had been in. Consequently, the research assistant needed to ask some additional questions to determine what cell the participant was in. These questions were asked while the participant made his/her jelly bean choices. A second research assistant surreptitiously recorded the number of jelly beans selected. The participant was then dismissed and later debriefed.

Results and Discussion

As predicted, there was a significant cognitive load by name type interaction on quantity taken $(F(1,96)=5.34, p<.05$, see table 1$)$. Participants took more ambiguously-named jelly 
beans than common-descriptive-named jelly beans, but only when their cognitive resources were unconstrained. When cognitive resources were constrained, there were no differences in the amount of jelly beans taken $(p>.5)$.

\section{INSERT TABLE 1 HERE}

The results from this pilot study suggest that the type of flavor name can influence product choice. In addition, there is evidence that the effect is cognitive. However, because we wanted the product decision to appear natural, we were unable to ask questions that might further enable us to understand the specific cognitive mechanism underlying participants' decisions. In the second pilot study, we shift to hypothetical decisions where we can more easily manipulate variables to better enable us to understand the underlying psychological processes.

\section{SECOND PILOT STUDY}

In this study, we seek to replicate our findings with a new product class involving color rather than flavor names. In addition, we look at the complete $2 \times 2$ matrix of color names. (See appendix for a complete listing of the color names used.) We predict, in the absence of any other indicator of the color shade, atypical color names will be more positively evaluated than typical color names. Further, if this preference is driven by incongruity, then unexpected-descriptive names will be preferred to common names, while if the Gricean hypothesis is operating, only ambiguous names should be preferred to common names. If an affective mechanism were to be operating, then any color name that employs vivid adjectives, regardless of whether they are specific or not, or typical or not, should be preferred to common names since they contain adjectives that could result in imagery and a positive response. 
Method

Participants were sixty undergraduates who participated in exchange for an opportunity to win one of two $\$ 50$ gift certificates to the campus store. The experiment was conducted via paper/pencil surveys. Participants were told that they had decided to order sweaters from a catalogue and were then presented with a list of available items and asked to indicate how many of each they would like. Participants were told to assume the style and material of the sweater was acceptable to them and that the sweater could be purchased in multiple styles.

Following their product decision, participants were asked to indicate their mood using the Peterson and Sauber (1983) Mood Short Form. Participants were then presented with a grid where the y-axis was labeled "very typical" (top) / "not at all typical" (bottom), and the x-axis was labeled "not at all specific" (left) / "very specific" (right). Participants were asked to place the seven colors they had seen on the grid. Finally, participants indicated their gender and familiarity with purchasing sweaters.

Results and Discussion

Manipulation Checks. There was a main effect of specificity such that the items that we classified as high specificity were rated more specific $(M=1.3)$ than the items that we classified as low specific $(M=-0.01, F(1,56)=6.96, p<.05)$. Similarly, there was a main effect of typicality such that the items we classified as high typical were rated more typical $(M=1.6)$ than the items we classified as less typical $(M=0.2, F(1,56)=10.13, p<.005)$. 
Effects of Specificity and Typicality. A two-way ANOVA revealed a significant effect of typicality on the number of items selected $(F(1,56)=5.58, p<.05)$, as predicted. Specifically, items that were low in typicality were selected more $(M=5.6)$ than the items that were high in typicality $(M=5.2)$. Planned contrasts revealed that participants selected significantly more items in the low specific, low typical (ambiguous) cell $(M=9.4)$ than in any of the other conditions (see table 2). In addition, although unexpected descriptive names $(M=6.6)$ were directionally selected more than common names $(M=5.2)$ this difference was not significant $(p$ $>$.4). There were no significant effects of typicality or specificity on the mood measure (F's $<$ $1)$.

\section{INSERT TABLE 2 HERE}

Discussion. In this study, we find that ambiguous names are preferred to more common names. Further, consistent with pilot study 1 , this preference does not appear to be due to the "vividness" of the adjectives used. Although this preference appears to be partially driven by the novelty of the items, novelty alone is not enough - the lack of specificity matters, too. Unexpected-descriptive names were not preferred to common names while ambiguous names were. These results are consistent with a Gricean mechanism, but they cannot completely rule out an incongruency mechanism as a main effect for low typicality was observed.

In the main experiment, we try to disentangle these two mechanisms by examining reactions to color names when the color shade is revealed or not revealed prior to seeing the color name. Although we use hypothetical choices, we try to increase the realism of the task by presenting pictures of real sweaters. In addition, we examine the effect of color names on a 
different dependent measure - satisfaction - which may be more reliable in this experimental setting and also provides some indication about whether such names could have long term effects.

\section{MAIN EXPERIMENT}

If the Gricean theory is correct, the advantage that ambiguous names have over more common names should be mitigated if the literal meaning of the name is interpretable, which would be the case if a picture of the actual color of the product was presented prior to the color name. If on the other hand, the name is presented first, followed by a picture, then the positive attributions will still be made about the ambiguous names (but not the common names) and the advantage would remain. Thus, the Gricean theory predicts that unspecific names will be preferred to high specific names when the name is presented first, but not when the name is presented second. In addition, the revelation of the color prior to the name should not impact responses for high specific names or typical, unspecific (i.e., common) names, but should cause a decrease in preference for atypical, unspecific (i.e., ambiguous) names.

The incongruency theory, in contrast, does not predict a decrease in preference for ambiguous names when a picture is presented before the name. Non-typical names are unfamiliar regardless of whether a picture is present or not, and consequently, the revelation of the color shade should not impact preference. The only exception to this would be if the presence of the shade increases curiosity about why the particular adjective was chosen. We would not expect curiosity to increase for typical names, as there is nothing surprising about this situation. Nor would we expect curiosity to increase for ambiguous names with a picture. However, for 
unexpected descriptive names, we could see an increase in preference when a picture is present. Without a picture, the consumer has to work to recall the specific shade that the adjective refers to and then try to determine if the descriptor makes sense. However, when the picture is presented first, this effortful recall step is removed, leaving the consumer to only have to determine whether the name fits. Thus, with the picture present, the "puzzle" is slightly easier, but still interesting enough to prompt elaboration. Thus, the incongruity theory predicts that low typical names should be preferred to high typical names and that the presence of a picture should increase preference for unexpected descriptive names, but not for any other name types.

While it is possible that the Gricean mechanism or the incongruency mechanism is the sole mechanism operating, the previous studies provide some evidence for both theories. We argue that this mixed evidence could arise because both theories operate, but under different circumstances. Specifically, we argue that the mechanism will depend on characteristics of the name itself, with low typical names where the literal meaning is discernable leading to an incongruency process while low typical names where the literal meaning is not discernable leading to a Gricean process. If this theory is correct, then we should see evidence of the Gricean theory for ambiguous names, while we see evidence of the incongruency theory for unexpected descriptive names. This would lead us to predict that the presence of a picture should hurt preferences for ambiguous names, but increase preferences for unexpected descriptive names. Thus, we predict:

H1: The presence of additional information about the color prior to the presentation of the color name will decrease preferences for ambiguous names (Gricean effect), but increase preferences for unexpected-descriptive names (Incongruency effect).

Method 
The experiment used a $2 \times 2$ (typicality x specificity color names, see appendix) x 2 (color picture presented before/after color name) between-subjects design administered on personal computers. One hundred and forty three undergraduates participated in the study as a class requirement. Participants were asked to imagine that they were ordering a sweater from a catalogue. They were either presented with six color names or six color swatches (pictures) and told, "Below are the available colors. Please examine them." Then, after a brief delay, the additional information (color swatch or name) appeared, and participants were asked to select one item they would like. Participants were then shown a picture of an actual sweater in a color that matched the one they had selected in the choice task. They were asked to indicate how satisfied they were with the sweater (11-point scale, "not at all satisfied" to "very satisfied"), how much they trusted the manufacturer (11-point scale, "not at all" to "very much"), and how likely they were to buy from the manufacturer again (11-point scale, "probably would not buy again" to "probably would buy again;" $\alpha=0.91$ ). Participants then answered additional questions about familiarity and whether they thought the names provided clues about the manufacturer. Latencies for time to make the purchase decision were also collected.

Results and Discussion

Manipulation Checks. There was a significant typicality by specificity interaction on familiarity $(F(1,135)=10.54, p<.005)$ such that ambiguous names $(M=4.1)$ were rated the least familiar (all $p$ 's $<.01)$, followed by unexpected descriptive names $(M=5.7 ; p<.0005$ compared to common names and $p<.10$ compared to common descriptive names), then common descriptive names ( $M=7.0 ; p<.10$ compared to common), and common names $(M=8.2)$. 
Effect of Specificity, Typicality, and Picture Order on Satisfaction. An ANOVA revealed a significant picture order by specificity 2 -way interaction $(F(1,135)=6.36, p<.05)$ as well as a significant picture order by specificity by typicality 3 -way interaction $(F(1,135)=4.95, p<.05)$. Specifically, as can be seen in table 3, viewing the picture first marginally reduced satisfaction for those viewing low specific names $(p<.10)$, but marginally increased satisfaction for those viewing high specific names $(p<.10)$.

\section{INSERT TABLE 3 HERE}

An analysis of the three-way interaction revealed that consistent with the Gricean hypothesis, viewing the picture first significantly reduced satisfaction for the ambiguous names $(p<.05)$, but not for any of the other name types (see table 4). However, consistent with the Incongruency theory, satisfaction was significantly higher for unexpected descriptive names when the picture was viewed first $(M=6.6)$ than when the name was viewed first $(M=4.4, p<$ .05). Taken together, these results support hypothesis1.

\section{INSERT TABLE 4 HERE}

Process Measures. There was a significant picture order by typicality interaction on the amount of time it took participants to make their initial sweater selection $(F(1,135)=6.05, p<$ $.05)$, such that those who saw low typical names prior to the picture $(M=28.2 \mathrm{msec})$ took significantly more time than any other cell (see table 5). This finding is consistent with the notion that consumers spend the most time elaborating on the given information in this condition.

INSERT TABLE 5 HERE 
In addition, there was a significant effect of typicality on beliefs that the names provided clues about the manufacturer $(F(1,135)=4.92, p<.05)$ such that those who saw low typical names believed this more strongly $(M=5.6)$ than those who saw high typical names $(M=4.6)$. There was also a marginally significant three-way interaction on this measure $(F(1,135)=3.37$, $p<.10$ ), such that those who saw ambiguous names prior to the picture believed the names provided clues more strongly than any of the other groups who saw the name first; there were no differences in beliefs for those who saw the picture first (see table 6).

\section{INSERT TABLE 6 HERE}

Summary. We find that the revelation of the color shade (through a picture of the color) prior to viewing the name decreases preference for ambiguous color names, but increases preference for unexpected descriptive color names. These results support the notion that when consumers encounter a surprising name (because it violates beliefs about informativeness), they engage in additional elaboration about the name to try to understand why it was provided. The type of elaboration will depend on how the name violates expectations - if the name is uninformative in a literal sense, consumers will engage in a Gricean process to determine the meaning of the communication; if the name is uninformative because it is atypical, consumers will search for the reason the particular adjective was selected as described by incongruency theory. The result of this additional elaboration is increased satisfaction with the product.

\section{GENERAL DISCUSSION}


The results from these studies suggest that color names can influence propensity of purchase, and that this effect is related to the typicality and specificity (or lack thereof) of the names and people's underlying assumptions that information in the marketplace should conform to certain norms. Although past research has examined many aspects of product attributes (e.g., missing attributes, irrelevant attributes (Carpenter, Glazer, and Nakamoto 1994), and number of attributes) and their effects on choices, to the best of our knowledge, no one has examined the effects of how the attribute levels are named. In addition, although researchers have suggested that people carry the assumptions of conversational norms into settings other than interpersonal conversation, no one has demonstrated that these norms also play a role in marketing communications.

In these studies, we demonstrate that the type of color name matters and that the source of this effect is cognitive in nature. While we cannot totally rule out any affective effects, we find no evidence for them. We also demonstrate that color names impact product decisions due to both the name's atypicality and its lack of specificity. The results of our main experiment show that when pictures of the color shade are shown prior to the exposure of the color name, satisfaction increases for unexpected descriptive names, which are atypical but specific (consistent with incongruency theory) but decreases for ambiguous names, which are atypical and unspecific (consistent with Gricean theory).

Taken as a whole, the results from these studies suggest that characteristics of the name may drive how people process them, with people using a process consistent with the incongruency theory when the source of norm violation is the provision of an unfamiliar (or atypical) name (as opposed to the normal expectation of a familiar name), but using a Gricean 
process when the source of norm violation is the lack of informativeness (or specificity) of the name. 


\section{APPENDIX}

Typology of Color/Flavor Names

\begin{tabular}{|c|c|c|}
\hline & Atypical & Typical \\
\hline Unspecific & Ambiguous & Common \\
\hline Specific & Unexpected Descriptive & Common Descriptive \\
\hline
\end{tabular}

\section{Flavors Used in Pilot Study 1:}

Common Descriptives: blueberry blue, cherry red, chocolate brown, marshmallow white, tangerine orange, and watermelon green.

Ambiguous: moody blue, Florida red, Mississippi brown, white Ireland, passion orange, and monster green.

\section{Colors Used in Pilot Study 2 and Main Experiment:}

Ambiguous: antique red, millennium orange, party yellow*, passion blue, lucky brown, friendly green, snuggly white

Unexpected Descriptive: Coke red, Florida orange, rainslicker yellow*, cookie monster blue, freckle brown, Kermit green, cotton white

Common: dark red, dark orange, light yellow*, light blue, light brown, dark green, pure white

Common Descriptive: cherry red, tangerine orange, lemon yellow*, baby blue, chocolate brown, pine green, ivory white

* Items marked with an asterisk were used in Pilot Study 2, but not the Main Experiment. 


\section{REFERENCES}

Carpenter, Greg S., Rashi Glazer, and Kent Nakamoto (1994), "Meaningful Brands from Meaningless Differentiation: The Dependence on Irrelevant Attributes," Journal of Marketing Research, 31 (August), 339-350.

Grice, H. Paul (1975), "Logic and Conversation," in Syntax and Semantics III: Speech Acts, ed. Peter Cole and Jerry L. Morgan, New York: Academic Press, 41-58.

Gruenfeld, Deborah H and Robert S Wyer, Jr. (1992), "Semantics and Pragmatics of Social Influence: How Affirmations and Denials Affect Beliefs in Referent Propositions," Journal of Personality and Social Psychology, 62, 38-49.

Harris, Richard Jackson and Gregory E. Monaco (1978), "Psychology of Pragmatic Implications: Information Processing between the Lines," Journal of Experimental Psychology: General, 107, 1-27.

Heckler, Susan E and Terry L. Childers (1992), "The Role of Expectancy and Relevancy in Memory for Verbal and Visual Information: What is Incongruency?" Journal of Consumer Research, 18 (March), 475-492.

Levinson, Stephen C (1983), Pragmatics, Cambridge, UK: Cambridge University Press. Mandler, George (1982), "The Structure of Value: Accounting for Taste," in Affect and Cognition: the $17^{\text {th }}$ annual Carnegie Symposium on Cognition, ed. Margaret Sydnor Clark and Susan T. Fiske, Hillsdale, NJ: Erlbaum, 3-36.

Meyers-Levy, Joan, Therese A. Louie, and Mary T. Curren (1994), "How Does the Congruity of Brand Names Affect Evaluations of Brand Name Extensions?” Journal of Applied Psychology, 79 (1), 46-53. 
Peterson, Robert A. and Matthew Sauber (1983), "A Mood Scale for Survey Research,” reprinted in Handbook of Marketing Scales (1993), ed. William Bearden, Richard Netemeyer, and Mary Mobley, Newbury Park, CA: Sage, 187-188.

Schultz, Connie (2001), "Nailing Down Just the Right Name," The Trenton Times, August 7, B1. Schwarz, Norbert (1996), Cognition and Communication: Judgmental biases, research methods, and the logic of conversation, Mahwah, NJ: Erlbaum. 
TABLE 1. EFFECT OF COGNITIVE LOAD AND NAME TYPE ON JELLY BEAN QUANTITIES (PILOT STUDY 1)

\begin{tabular}{|l|c|c|}
\hline & Ambiguous & Common Descriptive \\
\hline Low load & $18.0(3.0)^{\mathrm{a}, \mathrm{b}, \mathrm{c}}$ & $7.8(1.9)^{\mathrm{a}}$ \\
\hline High load & $6.1(1.9)^{\mathrm{b}}$ & $6.3(2.0)^{\mathrm{c}}$ \\
\hline
\end{tabular}

Note: numbers in parentheses are standard errors.

${ }^{a, b, c} \mathrm{p}<.005$ 
TABLE 2. MEAN NUMBER OF ITEMS CHOSEN (PILOT STUDY 2)

\begin{tabular}{|l|c|c|}
\hline & Low typical & High typical \\
\hline Low specific & $9.4(1.4)^{\mathrm{a}, \mathrm{b}, \mathrm{c}}$ & $5.2(0.7)^{\mathrm{a}}$ \\
\hline High specific & $6.6(1.3)^{\mathrm{c}}$ & $5.2(1.0)^{\mathrm{b}}$ \\
\hline
\end{tabular}

Note: numbers in parentheses are standard errors.

$$
\begin{aligned}
& { }^{a, b}, p<.05 \\
& { }^{c} p<0.1
\end{aligned}
$$


TABLE 3. EFFECT OF PICTURE AND SPECIFICITY ON SATISFACTION (MAIN EXPERIMENT)

\begin{tabular}{|l|c|c|}
\hline & Low Specific & High Specific \\
\hline Name first & $5.4(0.4)^{\mathrm{a}}$ & $4.6(0.4)^{\mathrm{b}}$ \\
\hline Picture first & $4.4(0.4)^{\mathrm{a}, \mathrm{c}}$ & $5.6(0.4)^{\mathrm{b}, \mathrm{c}}$ \\
\hline
\end{tabular}

Note: numbers in parentheses are standard errors.

$$
\begin{aligned}
& \text { a, b, } p<0.1 \\
& { }^{c} p<.05
\end{aligned}
$$


TABLE 4. MEAN RATINGS OF SATISFACTION BY CONDITION (MAIN EXPERIMENT)

\begin{tabular}{|l|c|c||c|c|}
\hline \multirow{2}{*}{} & \multicolumn{2}{|c||}{ Name 1st } & \multicolumn{2}{c|}{ Picture 1st } \\
\hline & Low Typical & High Typical & Low Typical & High Typical \\
\hline Low specific & $5.6(0.5)^{\mathrm{a}}$ & $5.2(0.5)$ & $3.9(0.6)^{\mathrm{a}, \mathrm{e}}$ & $4.9(0.6)^{\mathrm{c}}$ \\
\hline High specific & $4.4(0.6)^{\mathrm{b}}$ & $4.7(0.7)$ & $6.6(0.5)^{\mathrm{b}, \mathrm{c}, \mathrm{d}, \mathrm{e}}$ & $4.7(0.6)^{\mathrm{d}}$ \\
\hline
\end{tabular}

Note: numbers in parentheses are standard errors.

a, b, c $\mathrm{p}<.05$

${ }^{\mathrm{d}} \mathrm{p}<.01$

${ }^{\mathrm{e}} \mathrm{p}<.005$ 
TABLE 5. EFFECT OF PICTURE AND TYPICALITY ON SELECTION TIME (MAIN EXPERIMENT)

\begin{tabular}{|l|c|c|}
\hline & Low typical & High Typical \\
\hline Name first & $28.2(2.7)^{\mathrm{a}, \mathrm{b}, \mathrm{c}}$ & $19.5(1.5)^{\mathrm{b}}$ \\
\hline Picture first & $20.0(1.7)^{\mathrm{c}}$ & $21.7(2.2)^{\mathrm{a}}$ \\
\hline
\end{tabular}

Note: numbers in parentheses are standard errors.

${ }^{\mathrm{a}} \mathrm{p}<.05$

${ }^{b, c} \mathrm{p}<.01$ 
TABLE 6. MEAN BELIEFS THAT NAME GIVES CLUES ABOUT MANUFACTURER BY CONDITION (MAIN EXPERIMENT)

\begin{tabular}{|l|c|c||c|c|}
\hline \multirow{2}{*}{} & \multicolumn{2}{|c||}{ Name 1st } & \multicolumn{2}{c|}{ Picture 1st } \\
\hline & Low Typical & High Typical & Low Typical & High Typical \\
\hline Low specific & $6.4(0.5)^{\mathrm{a}, \mathrm{b}, \mathrm{c}}$ & $4.1(0.6)^{\mathrm{b}}$ & $5.1(0.6)$ & $5.6(0.6)$ \\
\hline High specific & $4.9(0.6)^{\mathrm{a}}$ & $4.1(0.7)^{\mathrm{c}}$ & $5.9(0.6)$ & $4.6(0.7)$ \\
\hline
\end{tabular}

Note: numbers in parentheses are standard errors.

${ }^{\mathrm{a}} \mathrm{p}<0.1$

${ }^{b, c} \mathrm{p}<.05$ 


\section{HEADINGS LIST}

1) ALTERNATIVE COGNITIVE THEORIES FOR EFFECTIVENESS OF COLOR OR FLAVOR NAMES

2) Theory of Conversational Implicature

2) Incongruency Theory

1) FIRST PILOT STUDY

2) Method

2) Results and Discussion

1) SECOND PILOT STUDY

2) Method

2) Results and Discussion

3) Manipulation Checks

3) Effects of Specificity and Typicality

3) Discussion

1) MAIN EXPERIMENT

2) Method

2) Results and Discussion

3) Manipulation Checks

3) Effect of Specificity, Typicality, and Picture Order on Satisfaction

3) Process Measures

3) Summary

1) GENERAL DISCUSSION

1) APPENDIX

1) REFERENCES 